\author{
دراسة اقتصادية لتقدير أثر التضخم على أداء أهم القطاعات الإنتاجية في الوطن العربي \\ أ. أ. د / سعيد عباس محمد رشاد \\ أ. أد / السيد حسن جادو \\ أستاذ الارشاد الززاعى ورئيس قسم الإتصاد الززاعي بكلية الزراعة دئة \\ بمثتهر - جامعة بنها \\ أستاذ الاقتصاد الزراعى - قسم الاقتصاد - كلية الزراعة بمثتهر \\ جامعة بنها \\ أحمد عبدالسلام جغيف الناصري \\ بكالوريوس العلوم الزراعية - كلية الزراعة- جامعة تكريت
}

Corresponding author: ahmedsalam123@gmail.com

المقدمة :

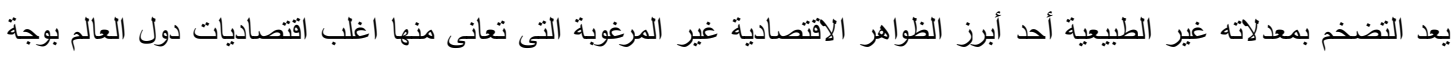

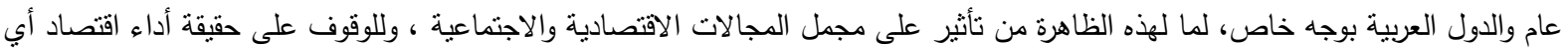

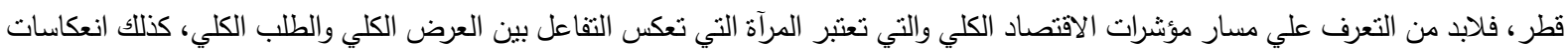

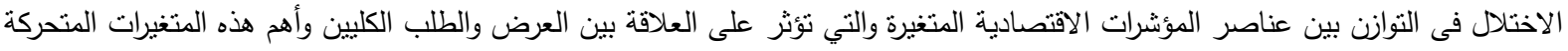

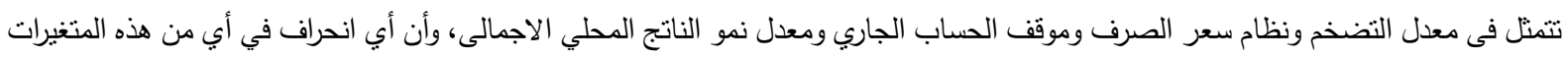

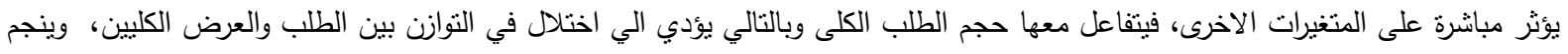

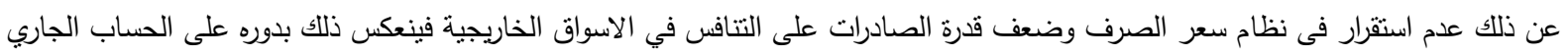

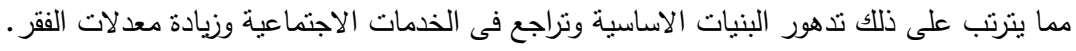

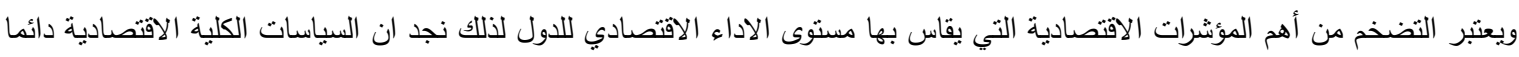

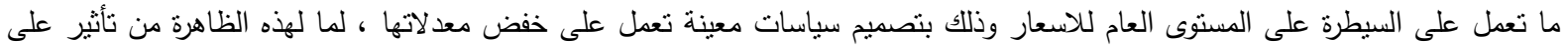

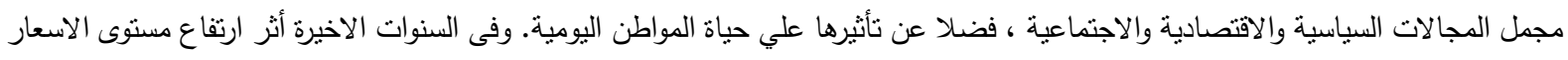

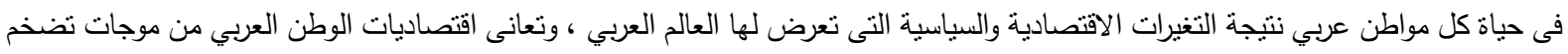

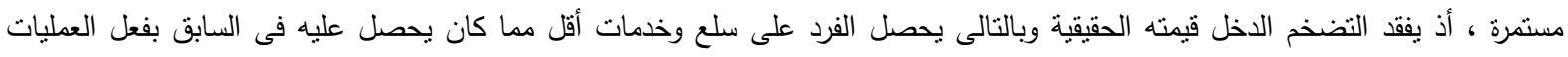
التضخمية. ومن ثم يتطلب أن تتخل الدولة بأدوات السياسة المالية من نفقات عامة وضرائب ودين عام والتى يكون هدفها المحافظة على المستوى

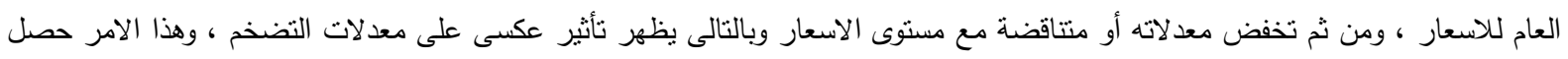

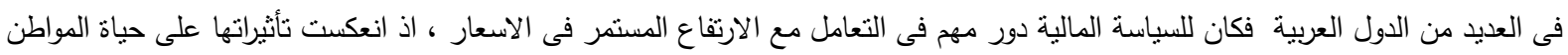
العربي وعلى مستوى الاقتصاد ككل.

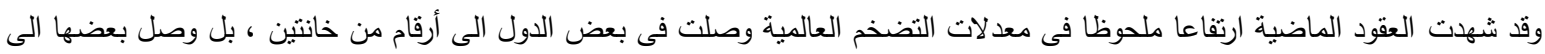

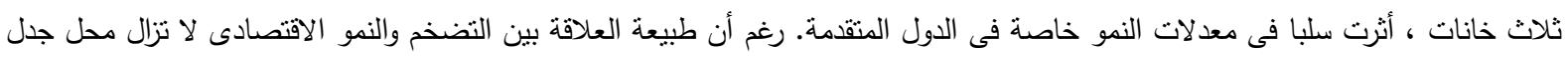

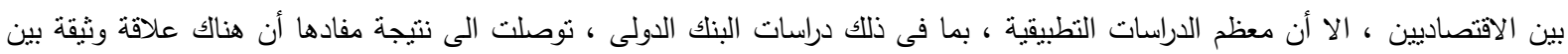

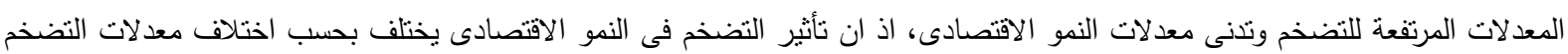
نفسها ، فقد وجد ان التضخم فى مستوياتها الدنيا ، وهذا حسب بعض الاتل الدراسات التى شملت الدول الصناعية الدتقدمة والدول النامية (1) .

مشكلة الاراسة : نظرا لاختلاف الظروف الاقتصادية والسياسية من حصار اقتصادى وضعف هيكلية الاقتصاد في العديد من الدول العربية ( العراق والسودان)

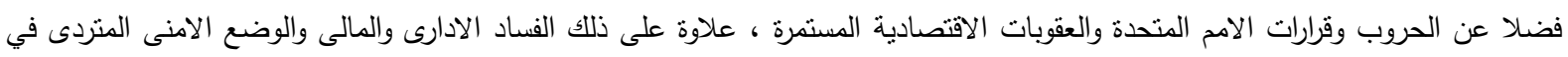

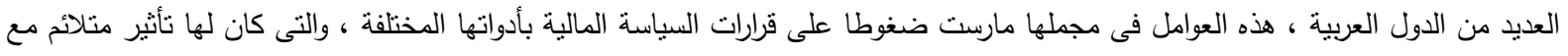

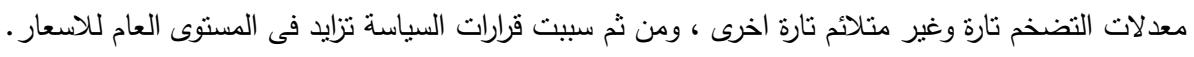

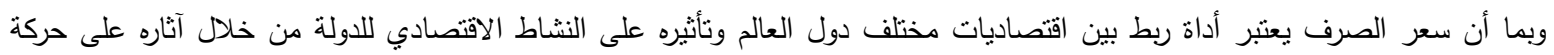

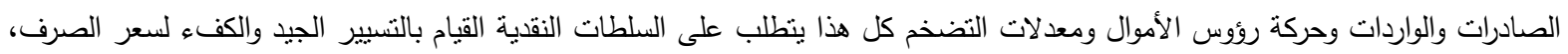

(1) محمد عبد الله الجراح ، *مصادر التضخم فى المملكة العربية السعودية** ، مجلة جامعة دمشق للعلوم الاقتصادية والقانونية ، المجلد 271 ، العدد الاول ، 2011 ، ص ص 139. 
وتبعا لهذا سوف نقدم معالم الإثكالية كما يلي: ينظر الي التضخم الي كونة ظاهرة اقتصادية ذات آثار سالبة على الاقتصاد بوجة عام في الدول المتقدمة والنامية علي حد سواء وبالتبعية يتأثر الاقتصاد في الوطن العربي بوجة خاص مناف التها آثار التصادية واخرى اجتماعية وسياسية وتكمن

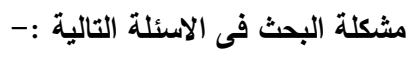

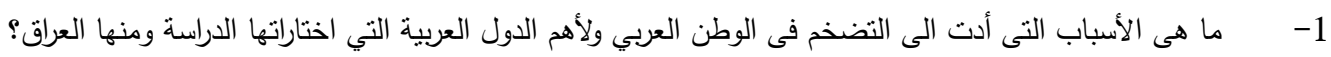

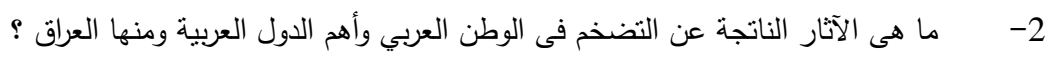

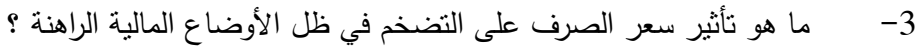
يتقرع هذا السؤال إلى مجموعة من التساؤلات الفرعية النالية:

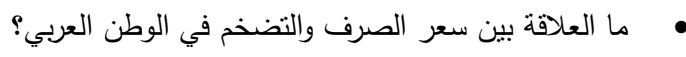

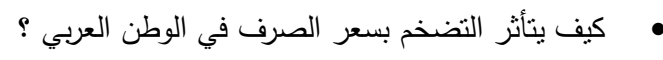

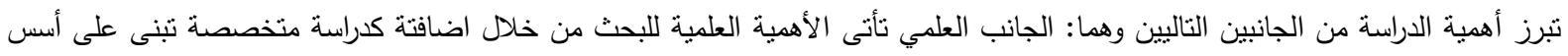

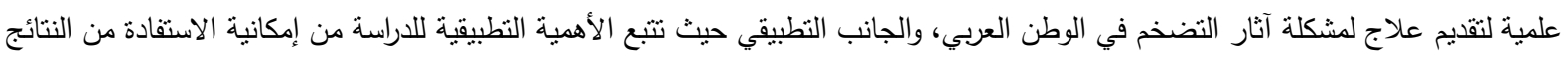

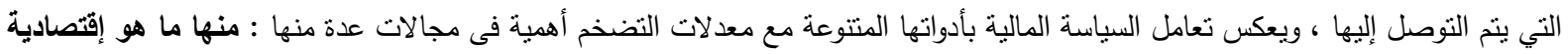

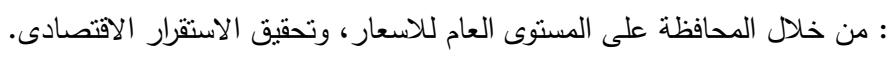
• أهمية تحديد نسبة التضخم حيث تستخدم البيانات التى تصدرها مؤشر أسعار المستهلك أو نسبة التضخم في عدة نواحي من قبل الحكومات والثركات، وتلعب دورا هاما في تحديد السياسات النقدية والمالية والاقتصادية للحكومات. يعد تحديد معدل التضخم مؤشرا هاما لأن معظم البنوك المركزية تستخدم التضخم لتحديد أسعار الفائدة وعادة ما يكون هناك نسبة تضات التخم

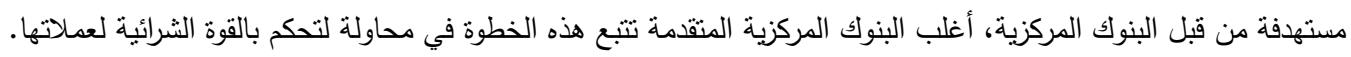

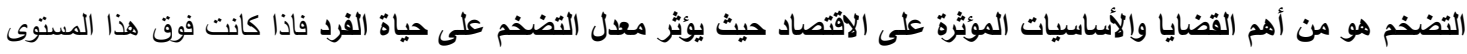

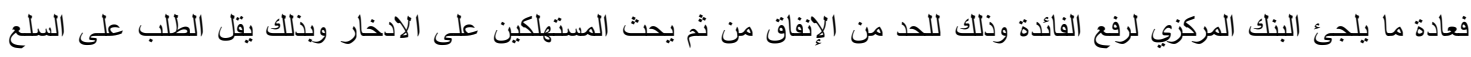
وتهبط الأسعار في النهاية والعكس إذا كانت نسبة النضخم القل من النشبة النئ المستهدفة.

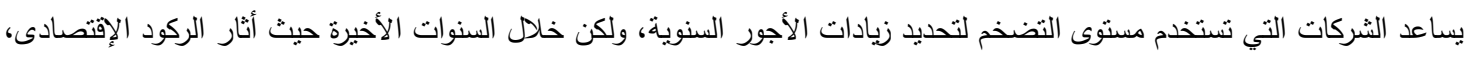

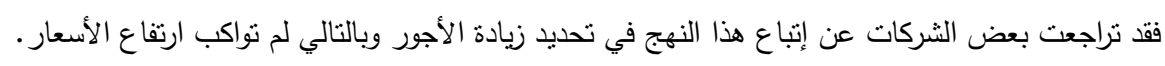

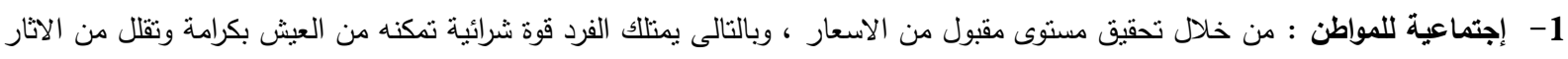
الاجتماعية الضارة للتضخم.

2- سياسية : بغرض تحقيق استقرار سياسى من خلال رضا الفرد عن الحالة الاقتصادية.

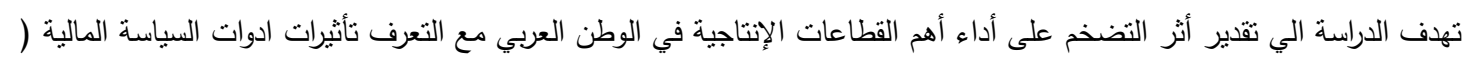

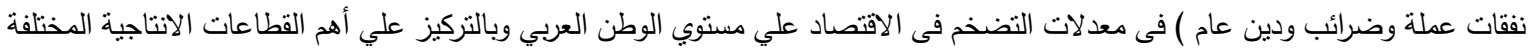

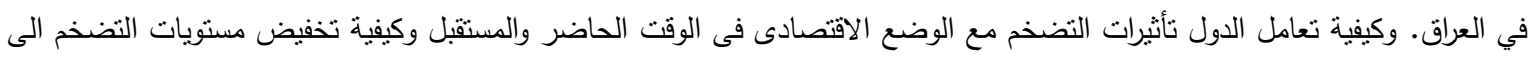
مستويات مرغوب فيها. ويتقرع من الهدف الرئيسي مجموعة من الاهداف الفرعية التالية:1 - التعرف علي مؤشرات التضخم فى الوطن العربي وبالتركيز علي العراق.

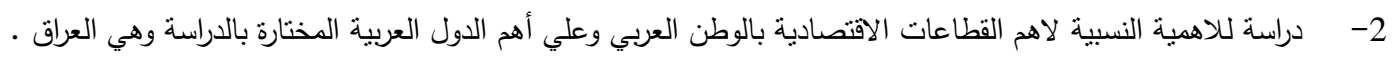

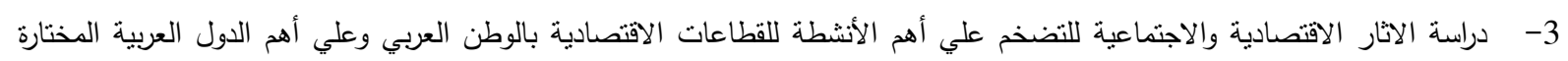
بالدراسة وهي العراق . 4- وضع بعض التصورات المستقبلية لعلاج الاثار السلبية للتضخم في الوطن العربي وأهم الدول العربية الني تضمنتها الدراسة.

تستند الدراسة الي فرضا رئيسيا يتمحور حول وجود علاقة ذات دلالة أحصائية بين أثز التضخم والنمو لأهم القطاعات الإنتاجية في

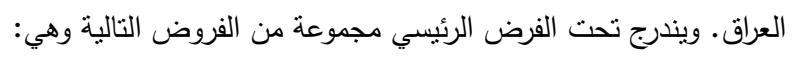




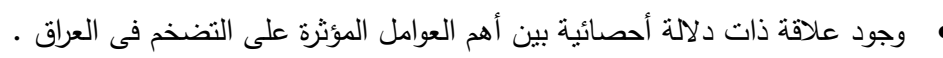

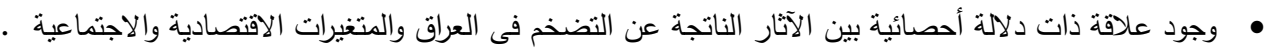

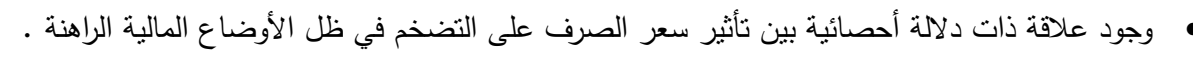

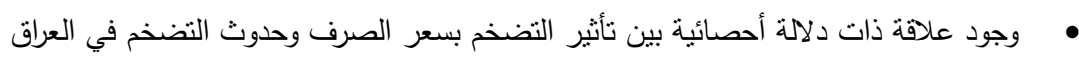

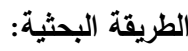
استخدمت الدراسة عددا من المناهج البحثية الوصفية والتحليلية منها الاستقرائي والاستتباطي، والتاريخي، والإحصائي، بحيث يمكن استخدام بعضها

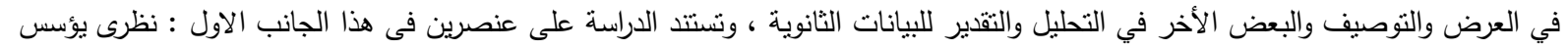

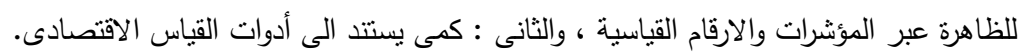
مدة البحث : يغطى البحث ثلاث فترات ، وهى : الاولى (1990 - 2003) ، ولثى ، الثانية : (2004 - 2018) .

\section{نتائج الاراسة ومناقشتها أولا- مساهمة القطاع الزراعى فى هيكل الناتج العربى الاجمالى:}

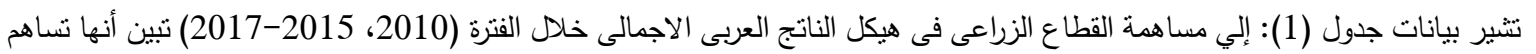

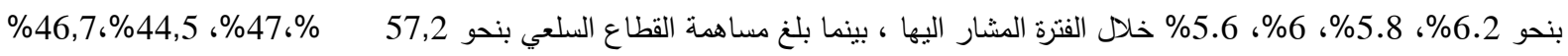

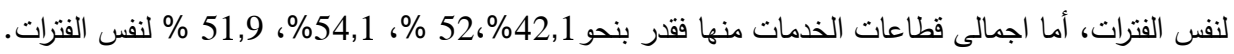

\begin{tabular}{|c|c|c|c|c|c|c|c|}
\hline \multicolumn{3}{|c|}{ معدل النمو السنوى بالاسعار الجارية * } & \multicolumn{4}{|c|}{ هيكل الناتج المحلى الاجمالى \% } & \multirow[b]{2}{*}{ القطاعات } \\
\hline $\begin{array}{c}-2016) \\
(2017\end{array}$ & $\begin{array}{c}-2015) \\
(2016\end{array}$ & $\begin{array}{r}-2010) \\
(2015\end{array}$ & 2017 & 2016 & 2015 & 2010 & \\
\hline 8,8 & $8,2-$ & $0,8^{-}$ & 46,7 & 44,5 & 47 & 57,2 & قطاعات الانتاج السلعى منها \\
\hline $2,8^{-}$ & 0,4 & 1,8 & 5,6 & 6 & 5,8 & 6,2 & 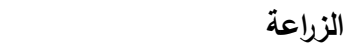 \\
\hline 21,5 & $16,7-$ & $5,7-$ & 21,7 & 18,5 & 21,5 & 33,9 & الصناعات الاستخراجية \\
\hline 0,5 & $3,8^{-}$ & 5,5 & 10,2 & 10,6 & 10,6 & 9,5 & الصناعات التحويلية \\
\hline 0,5 & 0,1 & 7 & 9,1 & 9,4 & 9,1 & 7,6 & باقى قطاعات الانتاج \\
\hline $0,4-$ & 0,7 & 7,7 & 51,9 & 54,1 & 52 & 42,1 & اجمالى قطاعات الخدمات منها \\
\hline $3,3^{-}$ & 3,3 & 2,7 & 14,3 & 15,3 & 14,4 & 11,3 & الخدمات الحكومية \\
\hline 4,4 & 89 & 4,8 & 1,8 & 1,8 & 0,9 & 0,9 & صافى الضرائب غير المباشرة \\
\hline 3,8 & $3,1-$ & 3,2 & 100 & 100 & 100 & 100 & الناتج المحلى الاجمالى \\
\hline
\end{tabular}

المصدر : جمعت وحسبت من بيانات : جامعة الدول العربية ، المنظمة العربية للتنمية الزراعية، الكتاب السنوي للإحصاءات الزراعية العربية أعداد مختلفة.

ثانيا - المؤشرات الاقتصادية في الوطن العربي:

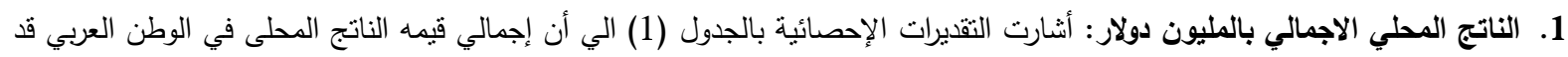

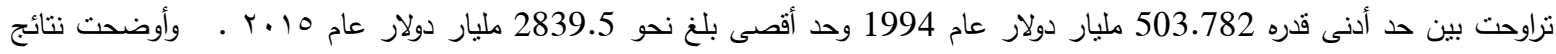

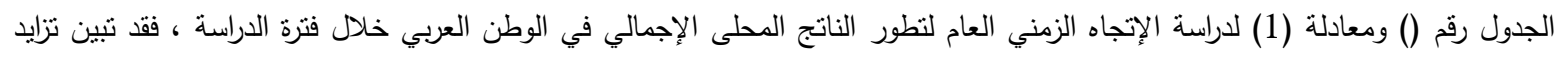

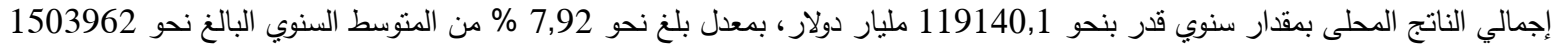

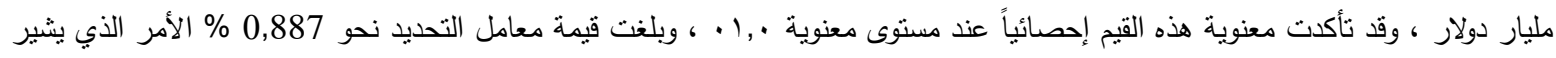
إلى أن 88,7 \% من هذا التزايد يرجع الى التغيرات التي يعكسها عامل الزمن. 
2-الناتج الززاعي الاجمالي بالمليون دولار: باستعراض بيانات جدول رقم (1) تيين أن الناتج الزراعي الاجمالي بالمليون دولار خلال الفترة

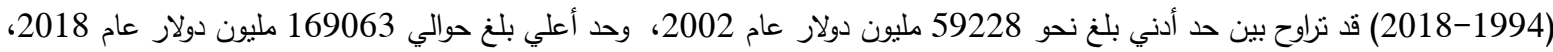

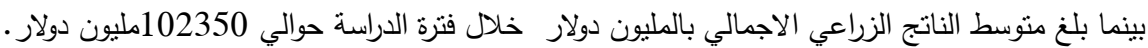

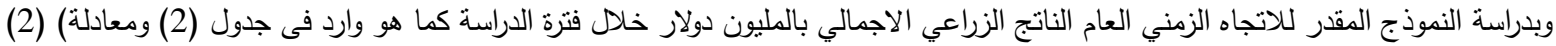

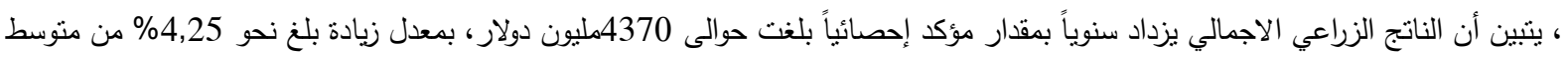

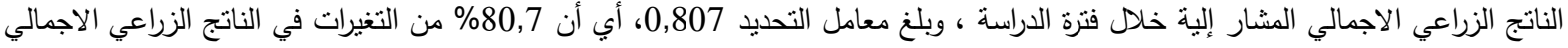
تزجع الي التغيرات التي يعكسها عامل الزمن.

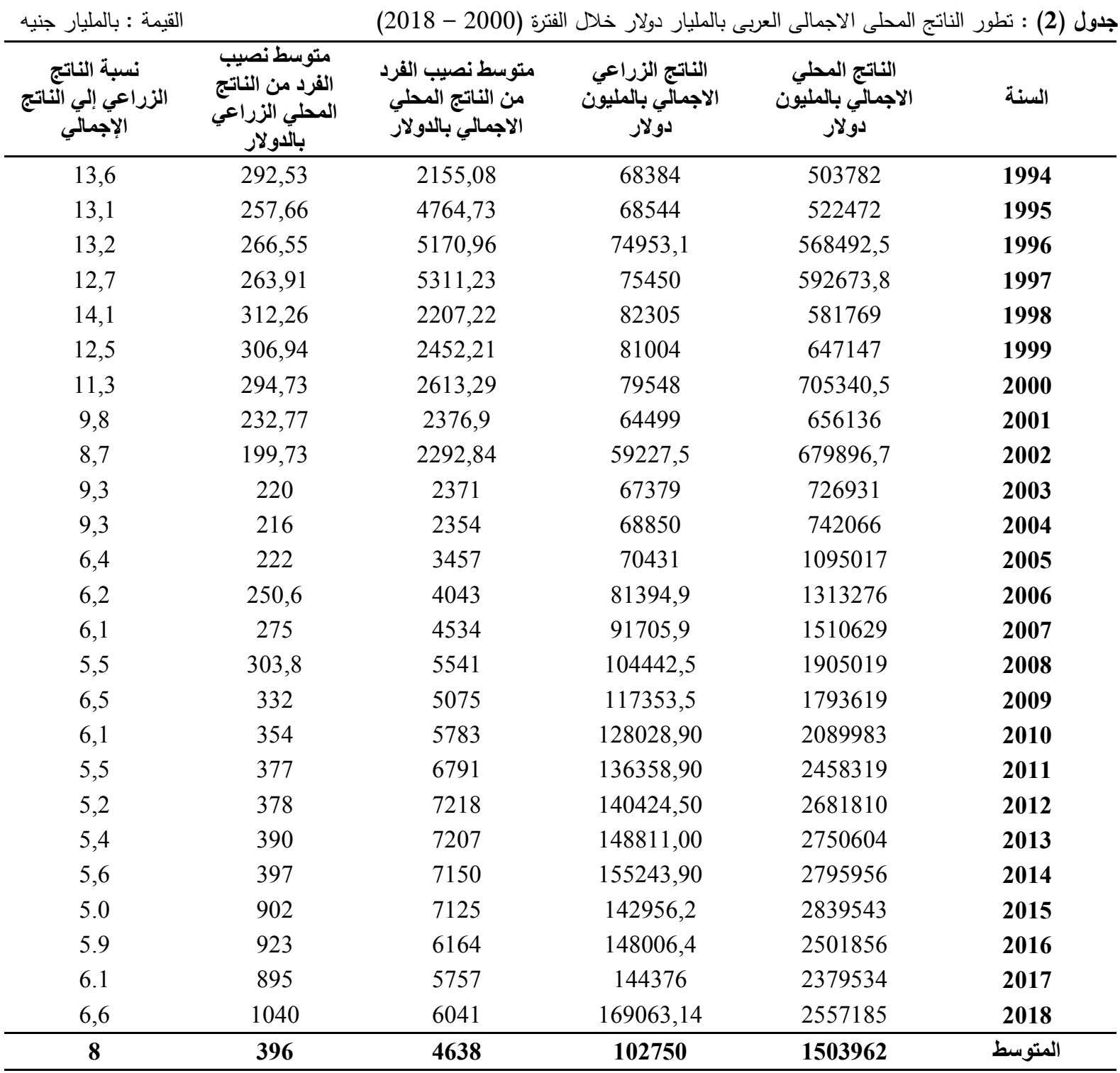

المصدر : جمعت وحسبث من بيانات : جامعة الدول العربية ، المنظمة العربية للتمية الزراعية، الكتاب السنوي للإحصاءات الزراعية العربية ـ أعداد مختلفة.

3-متوسط نصيب الفرد من الناتج المحلي الاجمالي بالاولار تنشير بيانات جدول رقم (1) الي أن منتوسط نصيب الفرد من الناتج المحلي الاجمالي بالدولار خلال الفترة (1994-2018) قد تراوح بين حد أدني بلغ نحو 2354 دولار عام 2004، وحد أعلي بلغ حوالي 7218 دولار عام 2012، بينما بلغ منتسط نصيب الفرد من الناتج المحلي الاجمالي خلال فترة الدراسة حوالي 4638 دولار . وبدراسة النموذج المقدر للاتجاه الزمني العام لمتوسط نصيب الفرد من الناتج المحلي الاجمالي دولار 
خلال فترة الدراسة كما هو وارد فى جدول (2) ومعادلة) (3) ، يتبين أن متوسط نصيب الفرد من الناتج المحلي الاجمالي يزداد سنوياً بمقدار مؤكد

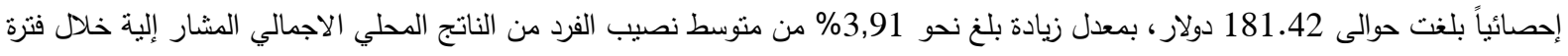

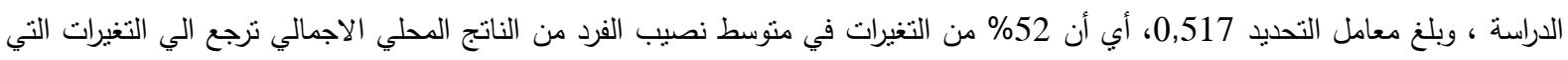
يعكسها عامل الزمن.

4-متوسط نصيب القرد من الناتج المحلي الزراعي بالدولار

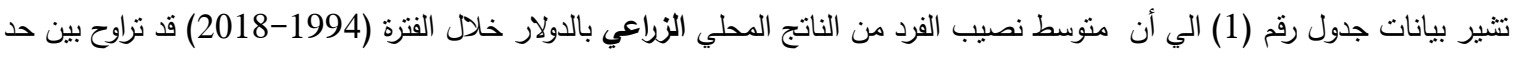

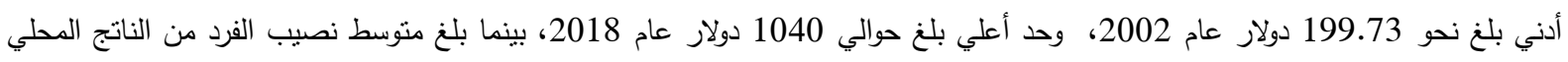

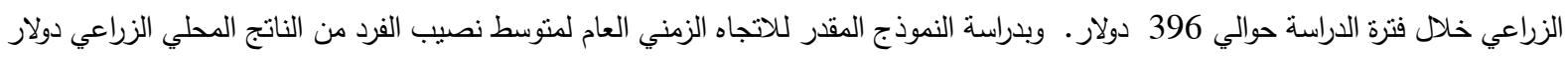
خلال فترة الدراسة كما هو وارد فى جدول (24.

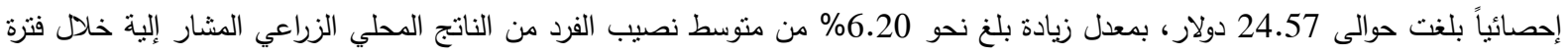

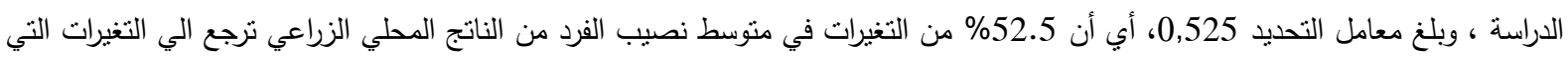
5-نسبة الناتج الزراعي إلي الناتج الإجمالي: تشير بيانات جدول رقم (1) الي أن نسبة الناتج الزراعي إلي الناتج الإجمالي خلال الفترة

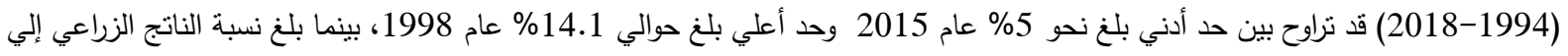

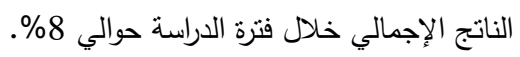

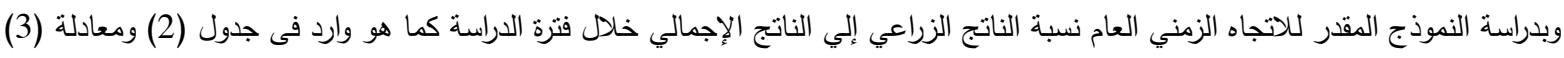

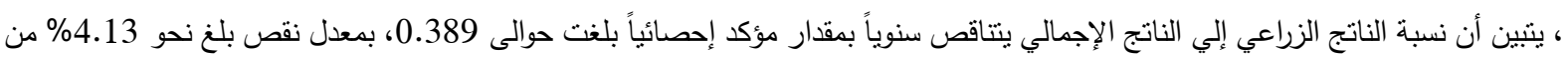

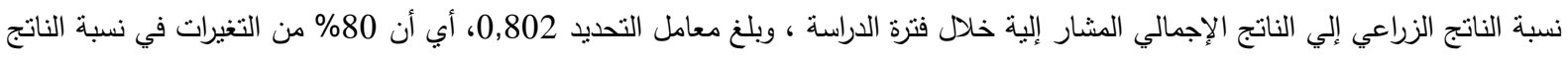
الزراعي إلي الناتج الإجمالي ترجع الي التغيرات التي يعكسها عامل الزمن.

\begin{tabular}{|c|c|c|c|c|c|c|}
\hline معدل التغير السنوي \% & F & R2 & متوسط الفترة & المعادلة & 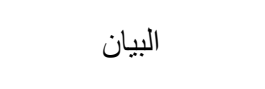 & المعادلة \\
\hline 7,92 & 172,9 & 0,887 & 1503962 & $\begin{array}{c}\hat{\mathrm{Y}}=62755+119140 \mathrm{x} \\
* *(13,15)\end{array}$ & الناتج المحلي الاجمالي & 1 \\
\hline 4,25 & 96,26 & 0,807 & 102750 & $\begin{array}{c}\hat{Y}=45942,3+4369,7 x \\
* *(9,81)\end{array}$ & الناتج المحلي الزراعي & 2 \\
\hline 3,911 & 24,67 & 0,517 & 4638 & $\begin{array}{c}\hat{\mathrm{Y}}=2279,7+181,42 \mathrm{x} \\
* *(4,97)\end{array}$ & من من الناتج المحلبي الفرد & 3 \\
\hline 6,20 & 25,4 & 0,525 & 396 & $\begin{array}{c}\hat{\mathrm{Y}}=76,64+24,57 \mathrm{x} \\
* *(5,04)\end{array}$ & من من الناتج المحليب الفرد & 4 \\
\hline 8,00 & 93,29 & 0,802 & 8 & $\begin{array}{c}\hat{Y}=13,45-0,389 x \\
* *(9,96-)\end{array}$ & نسبة الناتج الزر اعي & 5 \\
\hline
\end{tabular}
حيث تشير: x = القيمة الثقبيرية للمتغيرات في السنة,

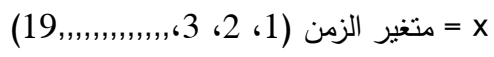

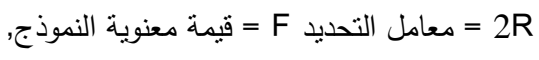

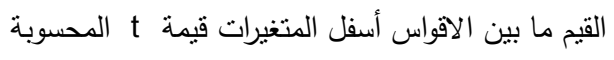

المصدر: جمعت وحسبت من بيانات جدول (2). 


\section{أهم المؤثرات الاقتصادية في الاقتصاد العراقي}

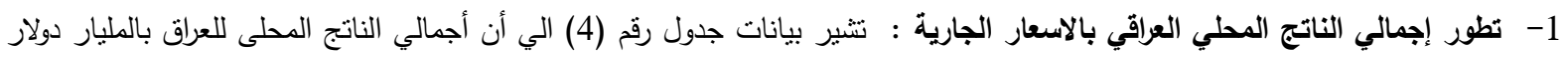

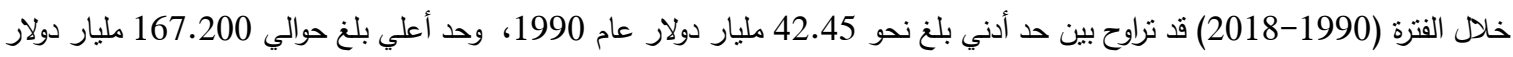

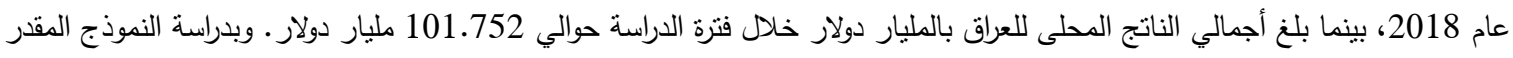

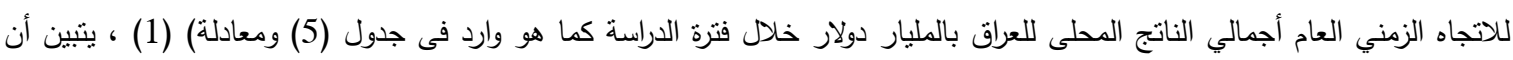

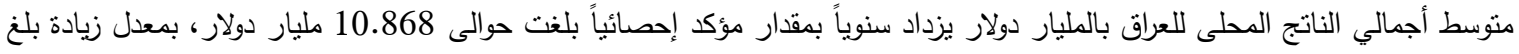

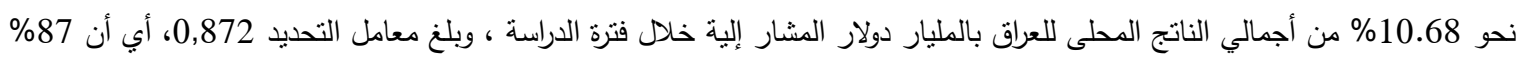

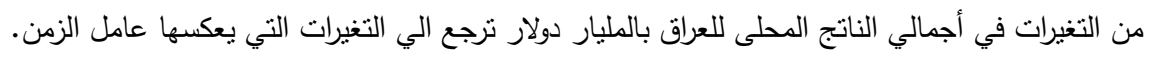

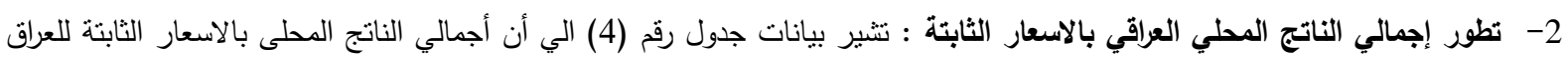
باللليار دولار خلال الفترة (1990-2018) قد تزاوح بين حد أدني بلغ نحو

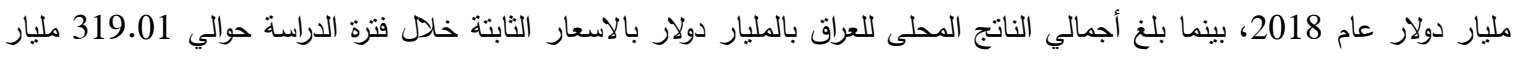

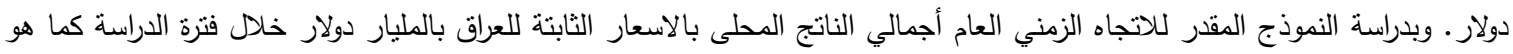

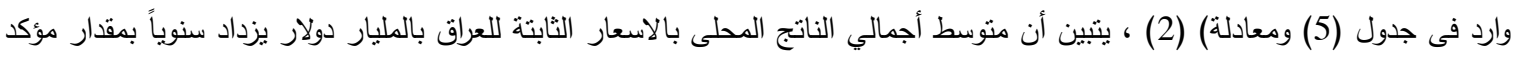

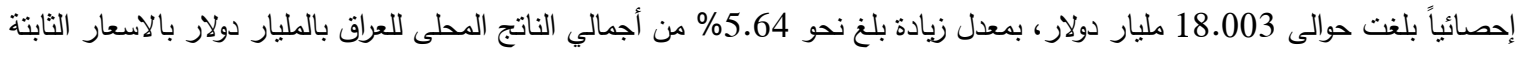

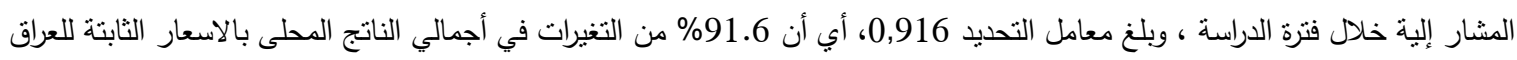

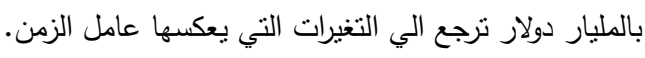

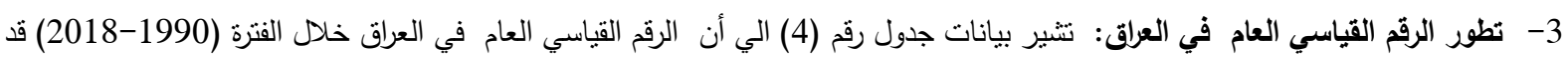

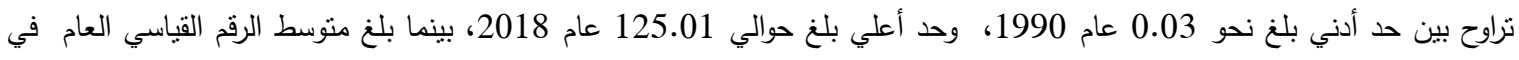

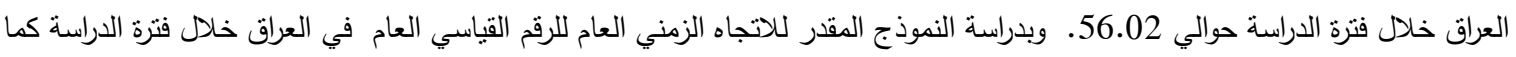

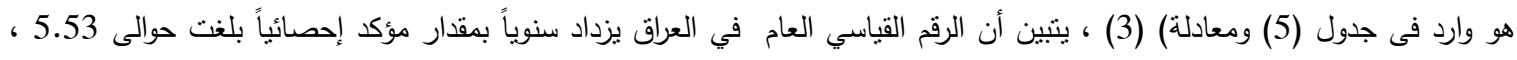

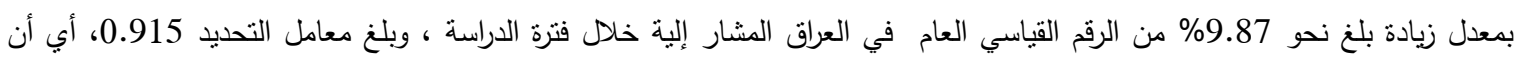

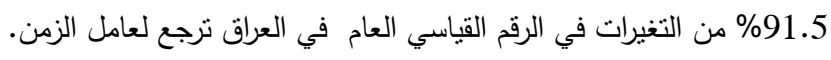

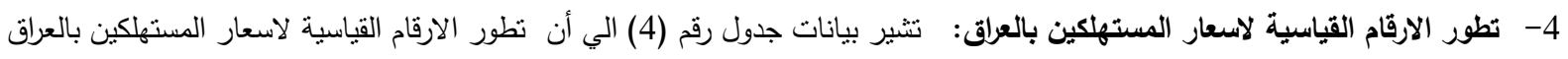

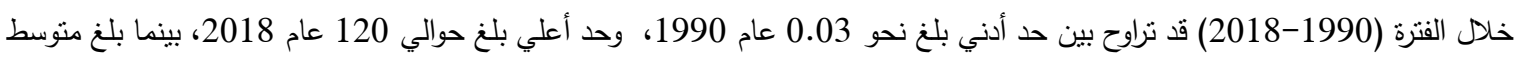

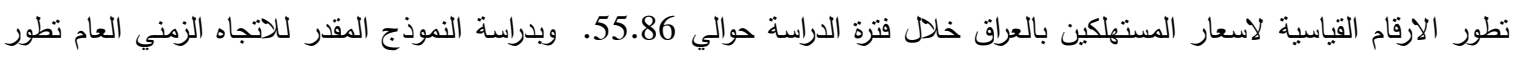

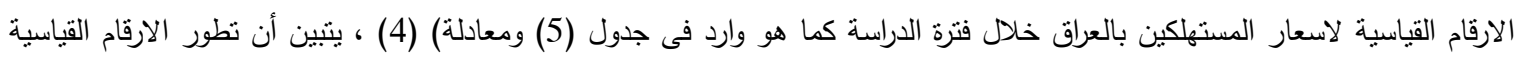

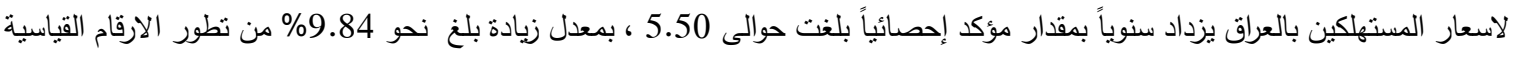

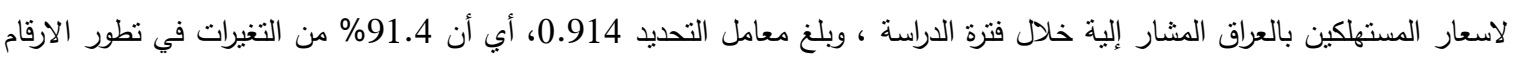
القياسية لاسعار المستهلكين بالعراق ترجع لعامل الزمن.

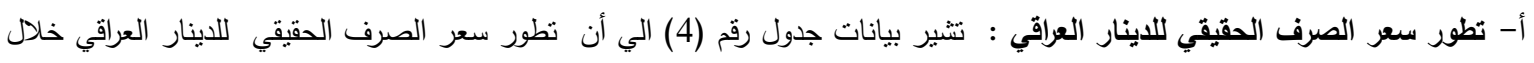

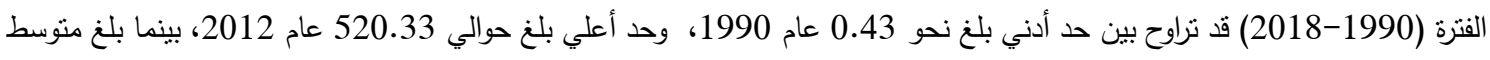
تطور سعر الصرف الحقيقي للاينار العراقي خلال فتزة الدراسة حوالي

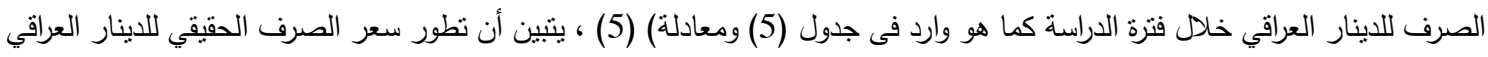

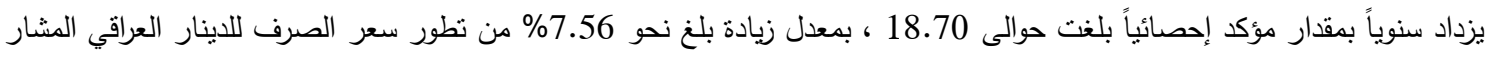
إلية خلال فترة الدراسة ، وبلغ معامل التحديد 0.820، أب أن 82\% من التغيرات في تطور سعر الصرف الحقيقي للاينار العراقي ترجع

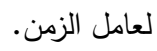
ب- تطور سعر الصرف للاينار العراقي : نثير بيانات جدول رقم (4) الي أن تطور سعر الصرف للاينار العراقي خلال الفترة (1990-

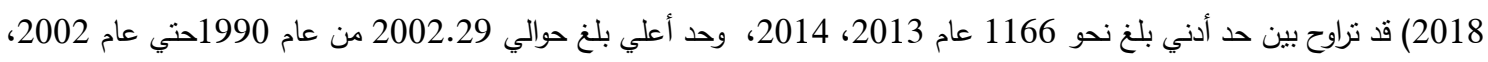

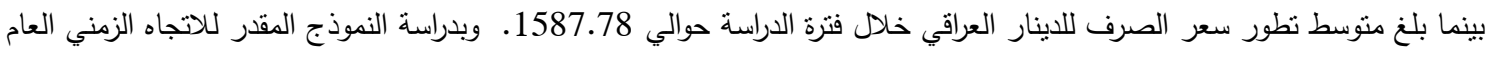

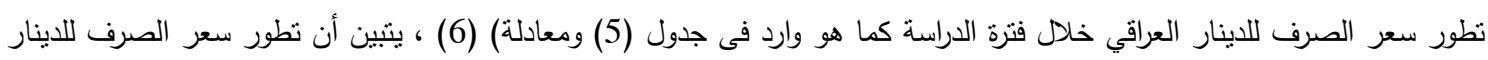

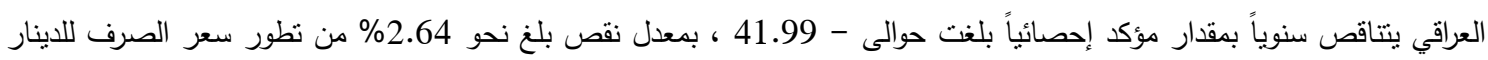


العراقي المشار إلية خلال فترة الدراسة ، وبلغ معامل التحديد 916.916، أي أن 6.691 من التغيرات في تطور سعر الصرف للاينار العراقي

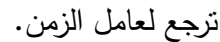

جدول (4) أهم المؤشرات الاقتصادية المؤثرة علي الاقتصاد القومي العراقي وعلاقتها بالتضخم خلال الفترة (1990-2018)

\begin{tabular}{|c|c|c|c|c|c|c|c|c|}
\hline التضخم & عدد السكان & الثالثي & الصرف & الصقرف & المستهلكين & القياسي & المحلي & السنوات \\
\hline 90.50 & 235000 & 201.27 & 2002.39 & 0.43 & 0.03 & 0.03 & 55.93 & 1990 \\
\hline 180.95 & 238500 & 72.36 & 2002.39 & 0.87 & 0.07 & 0.07 & 42.45 & 1991 \\
\hline 83.62 & 240350 & 95.95 & 2002.39 & 1.75 & 0.13 & 0.13 & 115.11 & 1992 \\
\hline 207.69 & 2453 & 125.01 & 2002.39 & 3.66 & 0.40 & 0.40 & 321.65 & 1993 \\
\hline 448.50 & 248906 & 129.83 & 2002.39 & 17.80 & 2.20 & 2.20 & 1658.33 & 1994 \\
\hline 387.31 & 250121 & 132.58 & 2002.39 & 68.95 & 10.73 & 10.73 & 6695.48 & 1995 \\
\hline-16.12 & 251335 & 147.19 & 2002.39 & 59.21 & 9.00 & 9.00 & 6500.92 & 1996 \\
\hline 23.06 & 256942 & 178.45 & 2002.39 & 111.47 & 11.08 & 11.08 & 15093.14 & 1997 \\
\hline 14.77 & 264274 & 240.66 & 2002.39 & 92.75 & 12.72 & 12.72 & 17125.85 & 1998 \\
\hline 12.58 & 276145 & 282.97 & 2002.39 & 156.48 & 14.32 & 14.32 & 34464.01 & 1999 \\
\hline 4.98 & 282395 & 286.95 & 2002.40 & 219.91 & 15.03 & 15.03 & 50213.70 & 2000 \\
\hline 16.37 & 291258 & 293.57 & 2002.41 & 173.06 & 17.49 & 17.49 & 41314.57 & 2001 \\
\hline 19.32 & 296531 & 273.31 & 2002.37 & 181.70 & 20.87 & 20.87 & 41022.93 & 2002 \\
\hline 33.62 & 303298 & 182.84 & 1450.20 & 192.31 & 27.89 & 27.89 & 29585.79 & 2003 \\
\hline 26.96 & 308891 & 281.87 & 1453.42 & 218.58 & 35.40 & 35.40 & 53235.36 & 2004 \\
\hline 36.96 & 316789 & 294.27 & 1472.00 & 280.46 & 48.49 & 48.49 & 73533.60 & 2005 \\
\hline 53.25 & 324826 & 324.16 & 1467.42 & 321.24 & 74.31 & 74.31 & 95587.95 & 2006 \\
\hline 30.82 & 333179 & 328.63 & 1254.57 & 359.81 & 97.21 & 97.21 & 111455.81 & 2007 \\
\hline 2.67 & 343772 & 355.67 & 1193.08 & 459.45 & 99.80 & 99.80 & 157026.06 & 2008 \\
\hline-2.19 & 353396 & 367.69 & 1170.00 & 366.96 & 97.61 & 97.61 & 130643.20 & 2009 \\
\hline 2.45 & 361377 & 391.23 & 1170.00 & 422.90 & 100.00 & 100.00 & 162064.57 & 2010 \\
\hline 5.60 & 361994 & 420.75 & 1170.00 & 516.52 & 105.60 & 105.60 & 217327.11 & 2011 \\
\hline 6.09 & 371527 & 479.39 & 1166.17 & 520.33 & 112.03 & 112.03 & 254225.49 & 2012 \\
\hline 1.88 & 381646 & 515.82 & 1166.00 & 511.46 & 114.14 & 114.14 & 273600.00 & 2013 \\
\hline 2.24 & 390629 & 519.43 & 1166.00 & 498.47 & 116.69 & 116.69 & 273600.00 & 2014 \\
\hline 1.39 & 398489 & 532.30 & 1167.33 & 364.47 & 118.32 & 118.32 & 207200.00 & 2015 \\
\hline 0.53 & 405857 & 604.55 & 1182.00 & 308.25 & 118.94 & 118.94 & 201200.00 & 2016 \\
\hline 0.18 & 413355 & 594.45 & 1184.00 & 349.70 & 119.16 & 119.16 & 228700.00 & 2017 \\
\hline-0.67 & 423297 & 598.20 & 1182.75 & 397.04 & 120.25 & 125.01 & 267200.00 & 2018 \\
\hline 57.77 & 307811.45 & 319.01 & 1587.79 & 247.45 & 55.86 & 56.02 & 101752.03 & المتوسط \\
\hline
\end{tabular}

المصدر جمعت وحسبت من بيانات البنك الدولي ( موقع البنك علي الثبكة القومية للانترنت). 
جدول (5) معادلات الاتجاه الزمني لنطور أهم المؤشرات الاقتصادية في العراق خلال الفترة (1990-2018)

\begin{tabular}{|c|c|c|c|c|c|c|}
\hline السنوي معدل التغير & $\mathrm{F}$ & $\mathrm{R} 2$ & منتوسط & المعادلة & البيان & المعادلة \\
\hline 10.68 & 184.7 & 0.872 & 101752 & $\begin{array}{c}\hat{\mathrm{Y}}=61264.1+10867.7 \mathrm{x} \\
* *(13,6)\end{array}$ & النالج المحلي الاجمالي & 1 \\
\hline 5.64 & 293.4 & 0.916 & 319.01 & $\begin{array}{c}\hat{\mathrm{Y}}=48.96+18,003 \mathrm{x} \\
* *(17.13)\end{array}$ & الناتج المحلي بالاسعار & 2 \\
\hline 9.87 & 264.3 & 0.915 & 56.02 & $\begin{array}{c}\hat{\mathrm{Y}}=-26.61+5,53 \mathrm{x} \\
* *(17,2)\end{array}$ & الرقم القياسي العام & 3 \\
\hline 9.84 & 285.8 & 0.914 & 55.86 & $\begin{array}{c}\hat{\mathrm{Y}}=-26.61+5,50 \mathrm{x} \\
* *(16.9)\end{array}$ & الارقام القياسية لاسعار & 4 \\
\hline 7.56 & 123.12 & 0.820 & 247.45 & $\begin{array}{c}\hat{\mathrm{Y}}-33.09+18,70 \mathrm{x} \\
* *(11.1)\end{array}$ & سعر الصرف الحقيقي & 5 \\
\hline 2.64 & 135.5 & 0.834 & 1587.8 & $\begin{array}{r}\hat{Y}=2217.6-41,99 x \\
* *(11.94-)\end{array}$ & سعر الصرف الجاري & 6 \\
\hline
\end{tabular}

$$
\begin{aligned}
& \text { حيث تنثير : Y = القيمة التقديرية للمتغيرات في السنة, }
\end{aligned}
$$

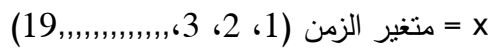

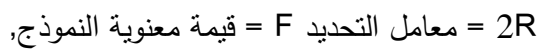

$$
\begin{aligned}
& \text { القيم ما بين الاقواس أسفل المتغيرات قيمة t المحسوبة } \\
& \text { المصدر : جمعت وحسبت من بيانات جدول (4). }
\end{aligned}
$$

1- نتائج مصفوفة الارتباط المتعلقة بالمؤثرات الاقتصادية ونسبة التضخم في العرلق خلال الفترة (1990-2018)

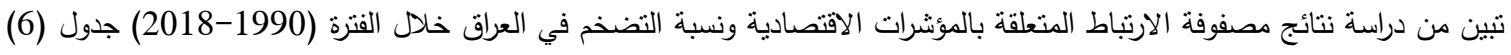

$$
\text { تبين الاتي }
$$

وجود ارتباط قوي موجب بين كل من الناتج المحلي والرقم القياسي حيث بلغ معامل الارتباط بينهما حوالي (0,956) وهذا بعني أن زيادة

$$
\text { الناتج المحلي يؤدي الي زيادة الرقم القياسي . }
$$

وجود ارتباط قوي موجب بين كل من الناتج المحلي والرقم القياسي للمستهلكين حيث بلغ معامل الارتباط بينهما حوالي (0,955) وهذا

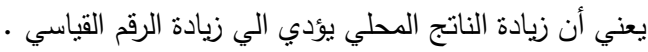

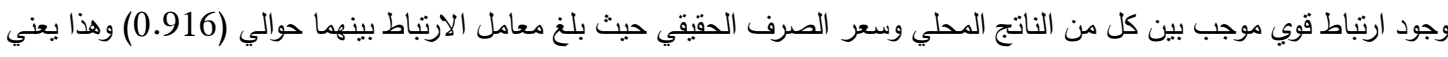

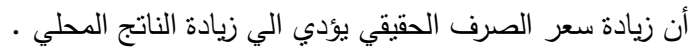

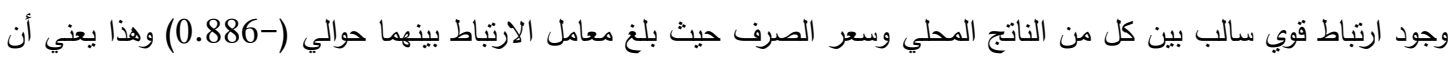
تناقص سعر الصرف يؤدي الي تناقص الناتج المحلي

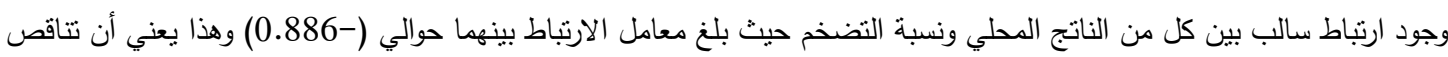

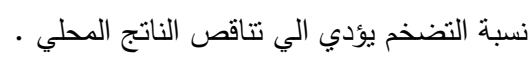

2- نتائج مصفوفة الارتباط المتعلقة بالمؤشرات الاقتصادية ونسبة التضخم في العراق خلال الفترة (1990-2002) تنين من دراسة ننائج

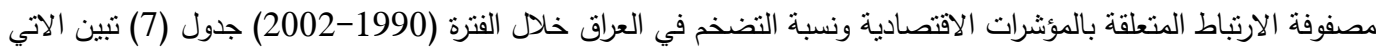

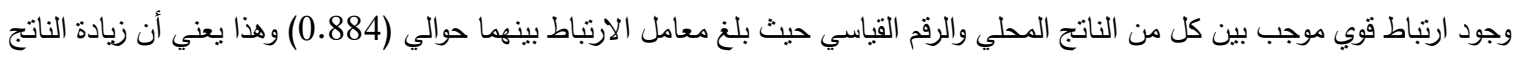

$$
\text { المحلي يؤدي الي زيادة الرقم القياسي . }
$$

وجود ارتباط قوي موجب بين كل من الناتج المحلي والرقم القياسي للمستهلكين حيث بلغ معامل الارتباط بينهما حوالي (0,884) وهذا بعني

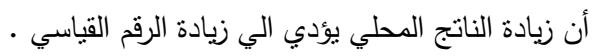

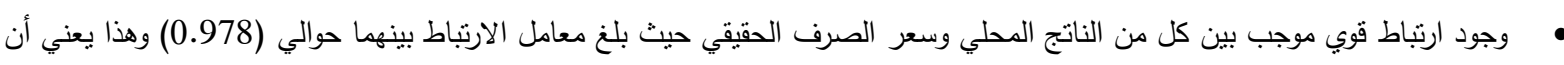

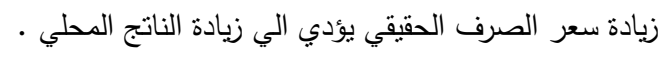


وجود ارتباط بين كل من الناتج المحلي وسعر الصرف حيث بلغ معامل الارتباط بينهما حوالي (0.428) وهذا يعني أن تتاقص سعر الصرف

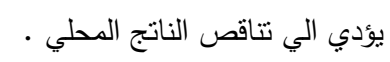

وجود ارتباط سالب بين كل من الناتج المحلي ونسبة التضخم حيث بلغ معامل الارتباط بينهما حوالي (-0.537) وهذا بعني أن تتاقص نسبة

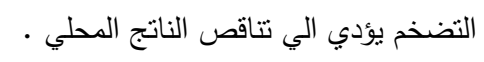

\begin{tabular}{|c|c|c|c|c|c|c|c|c|}
\hline التضخم & السكان & الناتج المحلي & الصرف & سعر الصرف & المستهلكين & القياسيم & المحاتي & المتغيرات \\
\hline \multirow[b]{8}{*}{$\begin{array}{c}1.00 \\
0\end{array}$} & & & & & & & 1.000 & الناتج المحلي \\
\hline & & & & & & 1.000 & 0.956 & الرقم القياسي \\
\hline & & & & & 1.000 & 1.000 & 0.955 & المستهلكين" \\
\hline & & & & 1.000 & 0.926 & 0.925 & 0.916 & سعر الصرق \\
\hline & & & 1.000 & -0.907 & -0.957 & -0.956 & -0.886 & سعر الصرّف \\
\hline & & 1.000 & -0.825 & 0.840 & 0.918 & 0.920 & 0.937 & الناتج المحلي \\
\hline & 1.000 & 0.828 & -0.779 & 0.791 & 0.820 & 0.821 & 0.797 & عدد السكان \\
\hline & -0.519 & -0.551 & 0.465 & -0.551 & -0.481 & -0.481 & -0.468 & التضخم \\
\hline
\end{tabular}

جدول (6) مصفوفة الارتباط بين المتغيرات الاقتصادية والاجنماعية وعلاقتها بالتضخم خلال الفترة (1990-2018)

المصدر : جمعت وحسبت من بيانات البنك الدولي ( جدول 4) باستخدام برنامج spss.

\begin{tabular}{|c|c|c|c|c|c|c|c|c|}
\hline التض & السكان & الناتج المحلي & الصرف & ستر الصرف & المستهلكين & القياستي & المحاتج & المتغيرات \\
\hline & & & & & 1.000 & $\begin{array}{l}1.000 \\
1.000\end{array}$ & $\begin{array}{l}1.000 \\
0.884 \\
0.884\end{array}$ & الرقم القياسي المحلي \\
\hline & & & & 1.000 & 0.936 & 0.936 & 0.978 & سعر الصرف \\
\hline & & & 1.000 & 0.394 & 0.196 & 0.196 & 0.428 & سعر الصرفف \\
\hline & & 1.000 & 0.374 & 0.876 & 0.825 & 0.825 & 0.900 & الناتج المحطي \\
\hline & 1.000 & 0.462 & 0.160 & 0.536 & 0.565 & 0.565 & 0.500 & عدد النكان \\
\hline $\begin{array}{c}1.00 \\
0\end{array}$ & -0.299 & -0.583 & -0.177 & -0.524 & -0.477 & -0.477 & -0.537 & التضخم \\
\hline
\end{tabular}

جدول (7) مصفوفة الارتباط بين المتغيرات الاقتصادية والاجتماعية وعلاقتها بالتضخم خلال الفنرة (1990-2002)

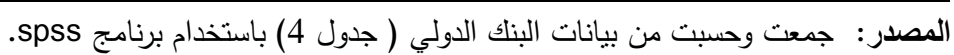

3-نتائج مصفوفة الارتباط المتعلقة بالمؤثرات الاقتصادية ونسبة التضخم في العلق خلال الفترة (2003-2018)

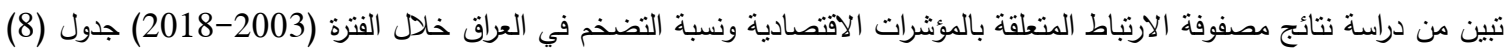

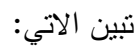

وجود ارتباط قوي موجب بين كل من الناتج المحلي والرقم القياسي حيث بلغ معامل الارتباط بينهما حوالي (0.87) وهذا يعني أن زيادة

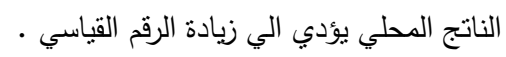
وجود ارتباط قوي موجب بين كل من الناتج المحلي والرقم القياسي للمستهكين حيث بلغ معامل الارتباط بينهما حوالي $(0,87)$ وهذا

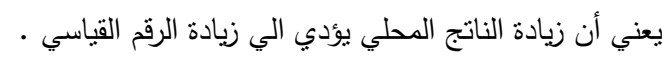

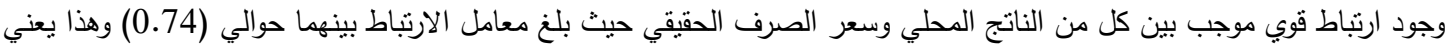

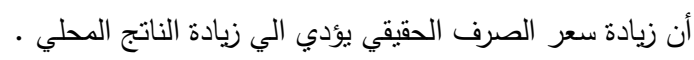

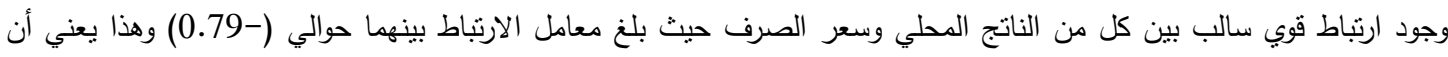

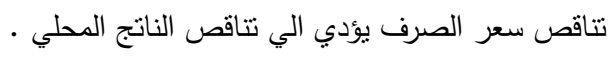


وجود ارتباط سالب بين كل من الناتج المحلي ونسبة التضخم حيث بلغ معامل الارتباط بينهما حوالي (-0.73) وهذا يعني أن تتاقص نسبة التضخم يؤدي الي تتاقص الناتج المحلي . يوجد ارتباط سالب قوي بين معدل أو نسبة التضخم والارقام القياسية والمستهلكين وسعر الصرف الحقيقي والناتج المحلي بالاسعار الثابتة

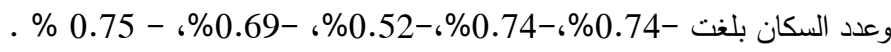

جدول (8) مصفوفة الارتباط بين المتغيرات الاقتصادية والاجتماعية وعلاقتها بالتضخم خلال الفترة (2003-2018)

\begin{tabular}{|c|c|c|c|c|c|c|c|c|}
\hline خم التض & السكان & الناتج المحلي & سعرف & سعر الصرف & المستهلكين & القياسي & المحلب النج & المتغيرات \\
\hline & & & & & & & 1.00 & الناتج المحلي \\
\hline & & & & & & 1.00 & 0.87 & الرقم القياسي \\
\hline & & & & & 1.00 & 1.00 & 0.87 & المستهلكين \\
\hline & & & & 1.00 & 0.64 & 0.63 & 0.74 & سعر الصرف \\
\hline & & & 1.00 & -0.70 & -0.91 & -0.90 & -0.79 & سعر الصرف \\
\hline & & 1.00 & -0.68 & 0.32 & 0.83 & 0.84 & 0.86 & الناتج المحلي \\
\hline & 1.00 & 0.98 & -0.75 & 0.36 & 0.87 & 0.88 & 0.86 & عدد السكان \\
\hline 1.00 & -0.75 & -0.69 & 0.91 & -0.52 & -0.74 & -0.74 & -0.73 & التضخم \\
\hline
\end{tabular}

\section{أثر معدل التضخم علي أهم المؤثرات الاقتصادية باستخدام العلاقات الانحدارية البسيطة العلاقة الانحدارية بين معدل التضخم والناتج المحلي بالاسعار الجارية}

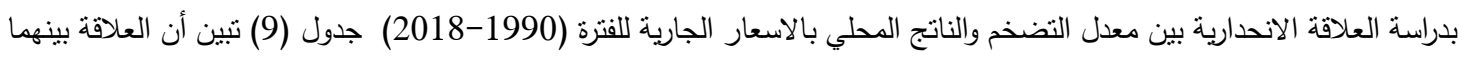
عكسية سالبة وقد ثبتت المعنوية الإحصائية عند مستوي 0,05 ويشير معامل التحديد الى أن 22\% من التغير في معدل التضخم سنويا ترجع إلي التغير في الناتج المحلي بالاسعار الجارية .

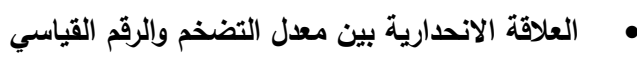

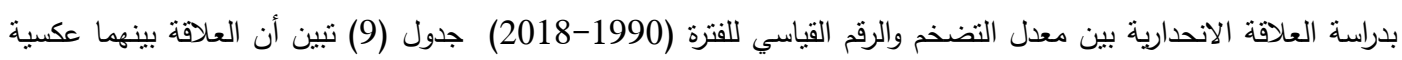
سالبة وقد ثبتت المعنوية الإحصائية عند مستوي 0,05 ويثنير معامل التحديد الى أن 23\% من التغير في معدل التضخم سنويا تزجع

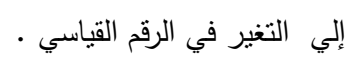
العلاقة الانحدارية بين معدل التضخم وأسعار المستهلكين بدراسة العلاقة الانحدارية بين معدل التضخم وأسعار المستهلكين للفترة (1990-2018) جدول (9) تبين أن العلاقة بينهما عكسية سالبة وقد ثبتت المعنوية الإحصائية عند مستوي 0,05 ويثير معامل التحديد الى أن 23\% من التغير في معدل التضخم سنويا ترجع إلي التغير في أسعار المستهلكين. العلاقة الانحدارية بين معدل التضخم وسعر الصرف الحقيقي بدراسة العلاقة الانحدارية بين العلاقة الانحدارية بين معدل التضخم وسعر الصرف الحقيقي للفترة (1990-2018) جدول (9)

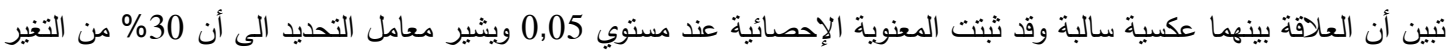

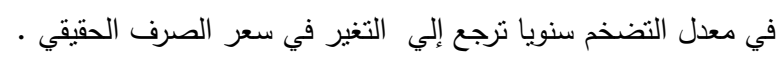

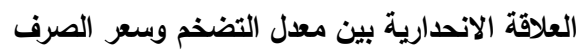
بدراسة العلاقة الانحدارية بين العلاقة الانحدارية بين معدل التضخم وسعر الصرف للفترة (1990-2018) جدول (9) تبين أن العلاقة بينهما موجبة وقد ثبت المعنوية الإحصائية عند مستوي 0,05 ويشير معامل التحديد الى أن 22\% من التغير في معدل التضخم

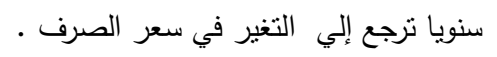




\section{العلاقة الانحدارية بين معدل التضخم والناتج المحلي بالاسعار الثابتة}

بدراسة العلاقة الانحدارية بين العلاقة الانحدارية بين معدل التضخم والناتج المحلي بالاسعار الثابتة للفترة (1990-2018) جدول

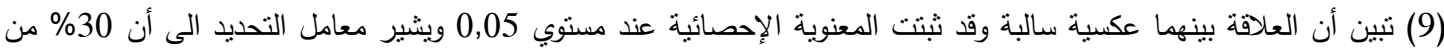

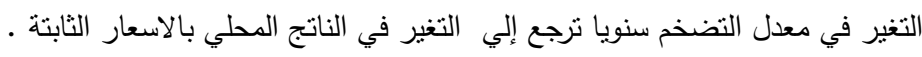

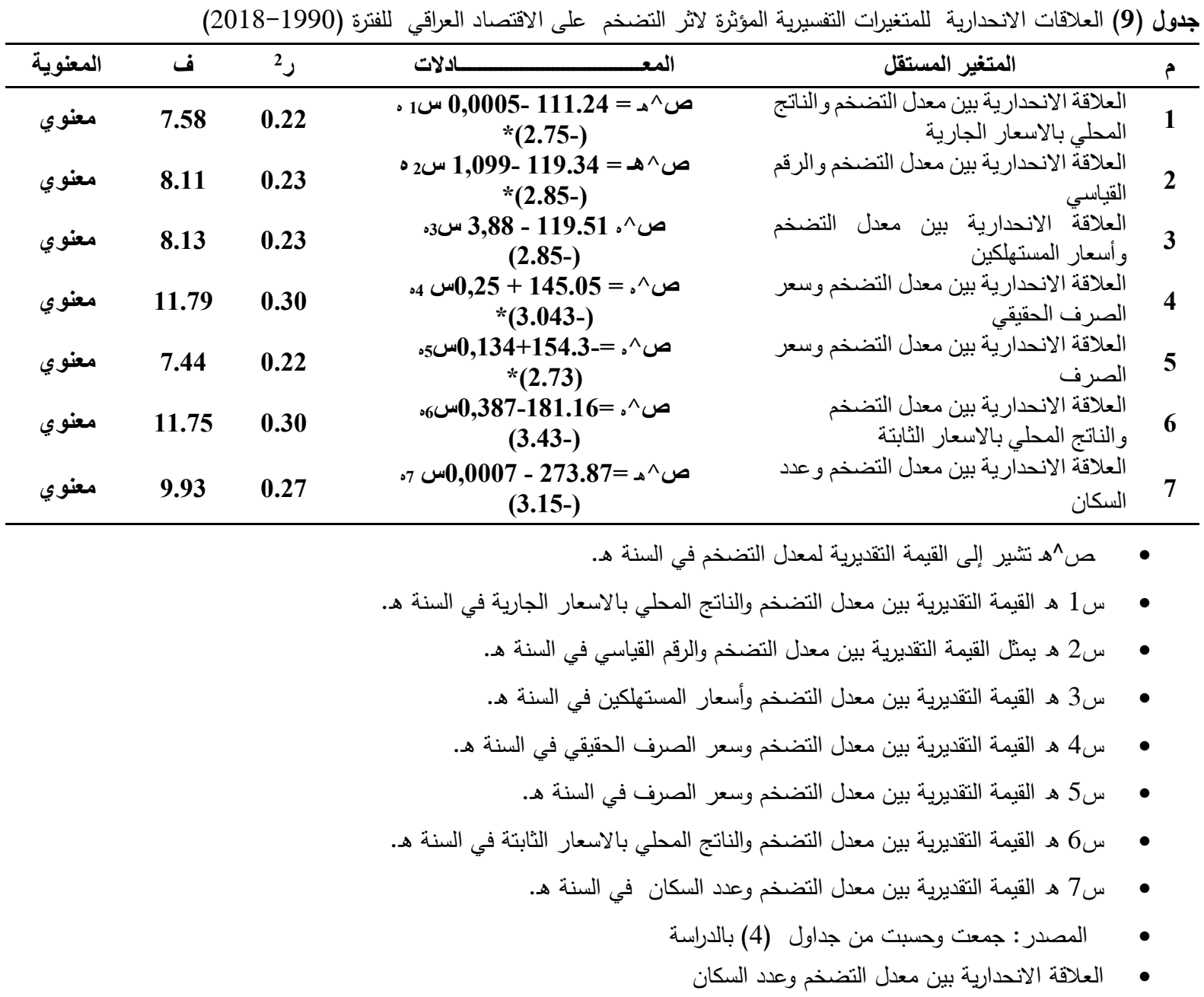

بدراسة العلاقة الانحدارية بين العلاقة الانحدارية بين معدل التضخم وعدد السكان (1990-2018) جدول (9) تبين أن العلاقة بينهما عكسية سالبة وقد ثبتت المعنوية الإحصائية عند مستوي 0,05 ويشير معامل التحديد الى أن 27\% من التغير في معدل التضخم سنويا ترجع إلي التغير في عدد السكان .

أثر معدل التضخم علي المؤثرات الاقتصادية الكلية

تم إجراء العديد من المحاولات للعلاقات الخطية المتعددة للمتغيرات التفسيرية التى تتضمنها الدراسة والتى يفترض تأثثرها على معدل التضخم فى العراق وطبقا للمعايير الاحصائية التى يجب توافرها فى النموذج، بالاضافة الى المنطقية الاقتصادية، فقد تم الحصول على أفضل هذه وله

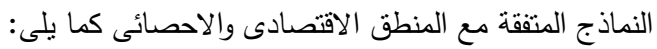

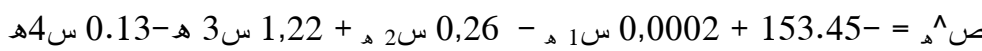

$$
\begin{aligned}
& \text { * }\left(2,11^{-}\right) \quad(1.11) \quad(0.24-) \quad *(2.22) \\
& \text { 0.21+ } \\
& 48.62=\mathbf{~} \quad \text { \& } \quad 0,977={ }^{2} \text {, }
\end{aligned}
$$


حيث (ص^ه) تشير إلى القيمة التقديرية لمعدل التضخم في صورة نسبة مئوية .

ص^هـ تثير إلى القيمة التقديرية لمعدل التضخم في السنة هـ. س1 هـ القيمة التقديرية بين معدل التضخم والناتج المحلي بالاسعار الجارية في السنة هـ. س2 هـ يمثل القيمة التقديرية بين معدل التضخم والرقم القياسي في السنة هـ. س3 هـ القيمة التقديرية بين معدل التضخم وأسعار المستهلكين في السنة هـ. س4 هـ القيمة التقديرية بين معدل التضخم وسعر الصرف الحقيقي في السنة هـ. س5 هـ القيمة التقديرية بين معدل التضخم وسعر الصرف في السنة هـ. س6 هـ القيمة التقديرية بين معدل التضخم والناتج المحلي بالاسعار الثابتة في السنة هـ. س7 هـ القيمة التقديرية بين معدل التضخم وعدد السكان في السنة هـ. وتتشير قيمة معامل التحديد الى ان نحو 97.7\% من التغير فى معدل التضخم في العراق انما يرجع تأثثرها الى المتغيرات التفسرية بالمعادلة،

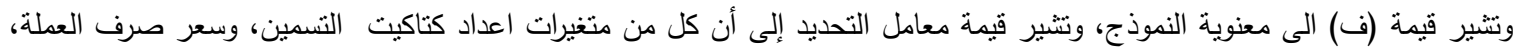
السعر المحلى للاجاج يفسروا نحو 97.7\% من التغير فى معدل التضخم في العراق يرجع الى عوامل غير مقيسة فى الدالة، وتتير النتائج

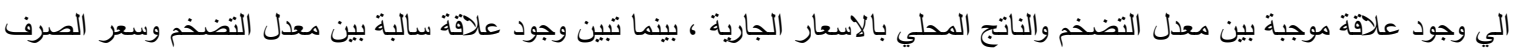
الحقيقي ، معدل التضخم وسعر الصرف ، معدل التضخم والناتج المحلي بالاسعار الثابتة وثثوت المعنوية الاحصائية للمنغيرات المشار أليها ، وتبين وجود علاقة غير بين معدل التضخم وباقي المتغيرات.

\section{الملخص باللغة العربية}

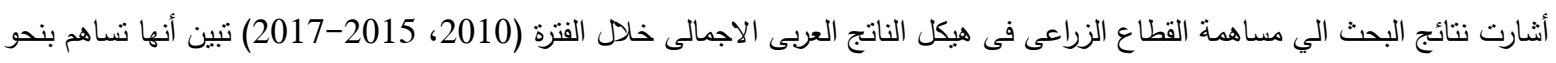

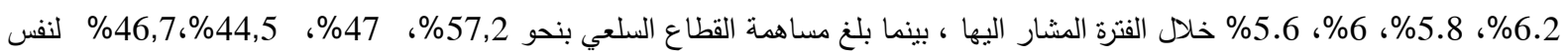

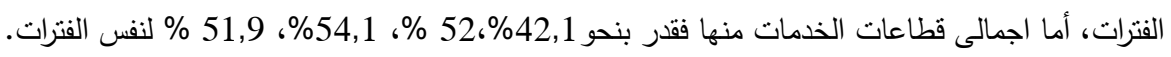
ونظرا للظروف القاسية التي مرت بها العراق فانها عجزت عن إيجاد آليات للسيطرة على أسعار السوق التي تحدد مستويات التضخم الجامح، الذي بات يهدد مستويات الدخل الحقيقي للفرد، وذلك على رغم اعتمادها سياسة نقدية انفردت بها على مستوى العالم عبر هيمنتها وفي شكل مطلق

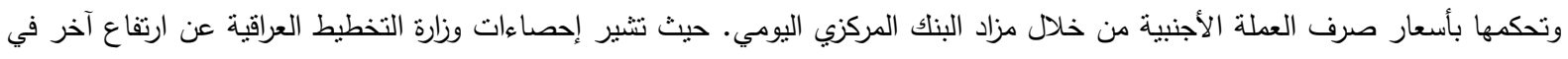
معدلات التضخم، شهده عام 2017 وبنسبة 0.8 في المئة عن معدلات 2016 ، ويُعتبر الرقم القياسي العام من أكثر المؤشرات استخداماً في قياس التضخم في العراق، إذ يعكس التغيير في أسعار السلع والخدمات للمستهلكين. ويرصد المؤشر 416 سلعة وخدمة يجمعها الجهاز المركزي

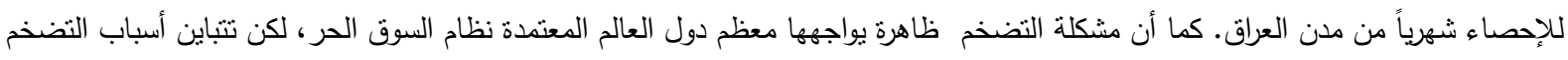
وأنواعه بين دولة وأخرى. إذ يحدث ارتفاع في قيمة سلعة محددة لكنه موقت في موسم أو مناسبة ستزول بعد فترة قصيرة، وهو لا يُعد تضخم الذي لئي يجب أن يتسم بالاستمرارية والثمول، ومشكلة النضخم في العراق، وهو يوصف دائماً بالمستمر والملموس في المستوى العام للأسعار ، نرك شعوراً

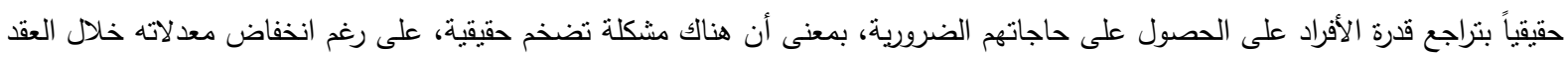

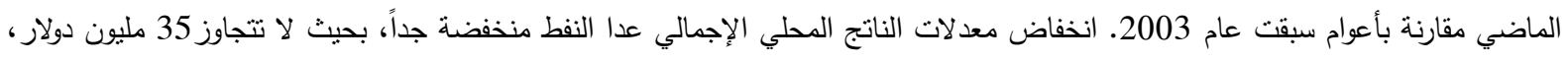
وهذا يؤدي إلى قصور في نشاطات العرض الكلي لقطاعات حيوية في الاقتصاد، منل الطاقة والوقود والنقل والمواصلات وقطاعات خدمية أخرى. أن التضخم زاد من أعباء العائلة العراقية، لأن العائلات التي تعيش من دون مورد مالي محدد قللت من استهلاكها وأعادت نرتيب أولوياتها الاستهلاكية، لعدم قدرتها على تغطية الزيادة في الأسعار الناجمة عن الارتفاع المستمر في أسعار بعض السلع وتحديداً المشتقات النفطية. ونتشير

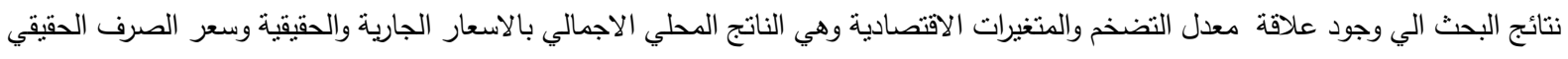




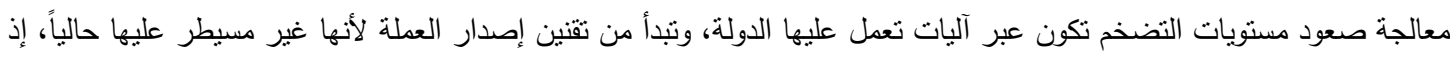

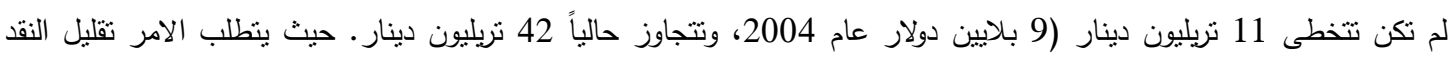

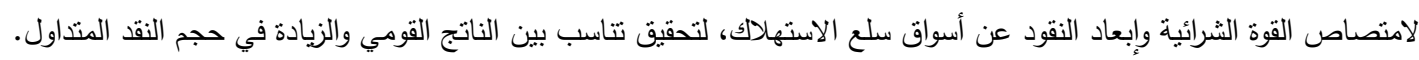

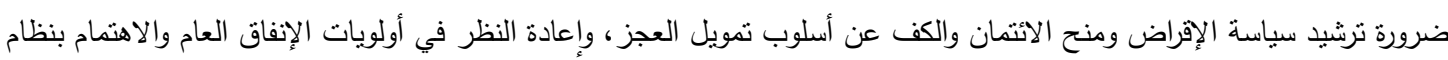

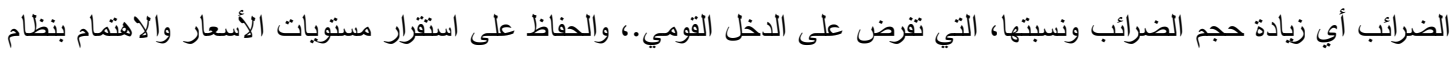

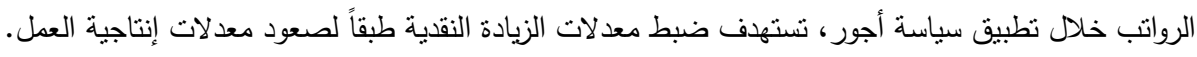

اميرة عبدالسلام محمد بشير ، محددات التضخم فى السودان خلال الفنرة (1980 -2008م)، جامعة السودان للعلوم والنكنولوجيا، رسالة الميرة عبداجعال

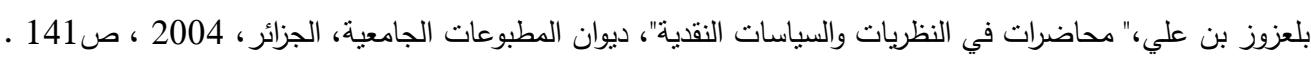

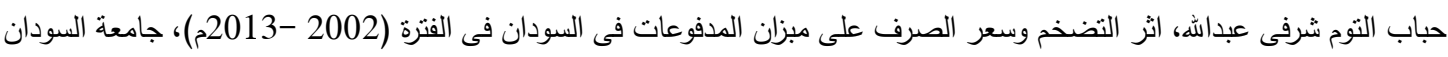
لللعلوم والتكنولوجيا، رسالة ماجستير غير منشورة، 2015.

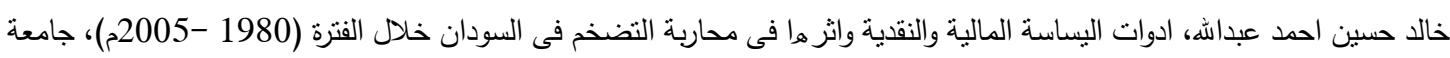

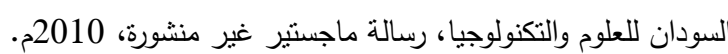
الدرديرى اسماعيل بلال، دور السياسة المالية والنقدية فى ضبط النضخم فى السودان فى الفترة (1970 -2006م)، جامعة السودان

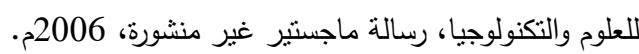

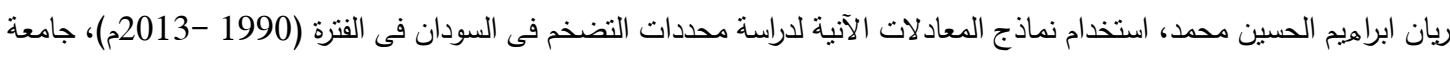

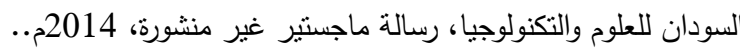
صندوق النقد الدولي (2018) قاعدة بيانات آفاق الاقتصاد العالمي الثبكة القورة القومية للانترنت.

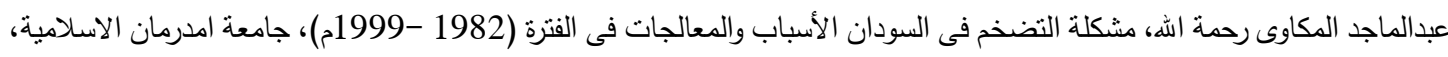
2002

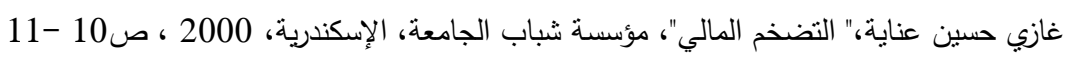

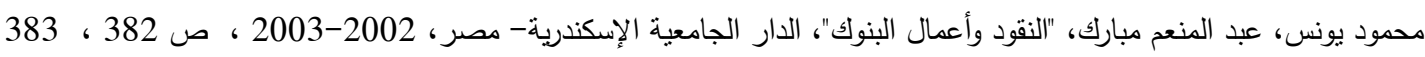

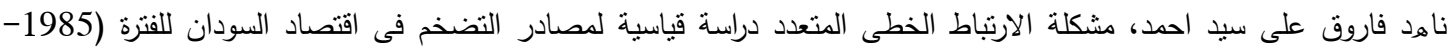

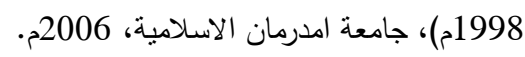
جامعة الدول العربية ، المنظمة العربية للتنمية الزراعية، الكتاب السنوي للإحصاءات الزراعية العربية - أعداد مختلفة. الثبكة القومية للانترنت. 


\title{
An Economic Study to Estimate the Impact of Inflation on the Performance of the Most Important Productive Sectors in the Arab World \\ El Sayed Hassan Gado ${ }^{1}$ - Saeed Abass Mohammed Rashad ${ }^{2}$ \\ Ahmed Abd El- Salam Jagheef Al-Nasiri ${ }^{3}$ \\ ${ }^{1}$ Professor of Agriculture Economics-College of Agriculture, Benha University. ${ }^{2}$ Prof. of Agricultural Extension, Faculty of Agriculture, Banha University \\ ${ }^{3}$ Bachelor of Agricultural Science - College of Agriculture - Tikrit University \\ Corresponding author: ahmedsalam123@gmail.com
}

\begin{abstract}
The results of the research indicated that the contribution of the agricultural sector to the structure of Arab GDP during the period $(2010,2015-2017)$ shows that it contributes about $6.2 \%, 5.8 \%, 6 \%$ and $5.6 \%$ during the mentioned period, while the contribution of the commodity sector reached $57.2 \%$. Total services sectors were estimated at $42.1 \%, 52 \%, 54.1 \%$ and $51.9 \%$ for the same periods .Given the harsh conditions that Iraq has gone through, it has been unable to find mechanisms to control market prices that determine the levels of hyperinflation, which now threatens the real income levels of the individual, despite the adoption of monetary policy unique in the world through its hegemony and in absolute form and governed by exchange rates Foreign through the daily central bank auction. Where the statistics of the Iraqi Ministry of Planning for another rise in inflation rates, witnessed in 2017 and by 0.8 percent from 2016 rates, and the general index is one of the most used indicators in measuring inflation in Iraq, reflecting the change in the prices of goods and services to consumers. The index monitors 416 goods and services collected by the Central Bureau of Statistics monthly from the cities of Iraq. The problem of inflation is a phenomenon faced by most countries in the world adopted a free market system, but the causes of inflation and types vary from one country to another. There is an increase in the value of a specific commodity, but it is temporary in a season or occasion that will disappear after a short period. There is a real inflation problem, although its rates have declined over the past decade compared to years before 2003. The drop in gross domestic product (GDP) except oil is so low that it does not exceed \$ 35 million. For vital sectors in the Economy, such as energy, fuel, transportation, and other service sectors. Inflation has increased the burdens of the Iraqi family, because families living without a specific financial resource have reduced their consumption and rearranged their consumption priorities because they are unable to cover the increase in prices resulting from the continuous rise in the prices of some commodities, especially oil derivatives. The results of the research indicate that there is a relationship of inflation rate and economic variables, the GDP of current and real prices and the real exchange rate
\end{abstract}

\section{Recommendations:}

Addressing the rise in inflation levels through state-operated mechanisms, starting from the legalization of currency issuance because it is not currently controlled, it did not exceed 11 trillion dinars (\$ 9 billion in 2004, and currently exceeds 42 trillion dinars. Purchasing and removing money from the markets of consumer goods, to achieve a proportionate between the national product and the increase in the volume of money in circulation. The need to rationalize the policy of lending and granting credit and stop the method of financing the deficit, and review the priorities of public spending and attention to the tax system, ie increase the size and proportion of taxes, which are imposed on national income. Cash increase rates according to the rise in labor productivity. 